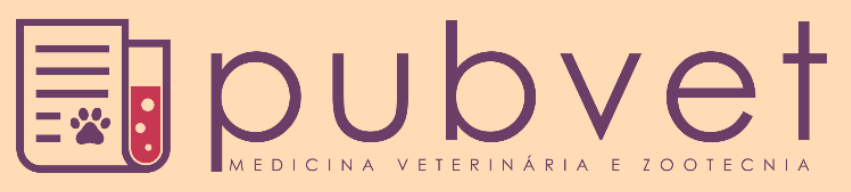

https://doi.org/10.31533/pubvet.v14n7a612.1-6

\title{
Avaliação química da silagem de grão de milho reidratado em diferentes níveis de adição de água
}

\author{
Matheus de Carvalho Benini ${ }^{1}$, Wellyngton Tadeu Vilela Carvalho ${ }^{2 *} \bullet$, Renata Vitarele Gimenes \\ Pereira $^{2}{ }^{\circ}$, Queila Gouveia Tavares ${ }^{3}{ }^{\circ}$, Duarte Carvalho Minighin ${ }^{4}{ }^{\circ}$, Ruley France de Jesus \\ Nunes $^{5}$, Luiz Paulo Fajardo Souza ${ }^{1}$, Carlos Henrique Milagres Ribeiro ${ }^{1} \bullet$, Lucas Vieira Silva ${ }^{1 \bullet}$ \\ ${ }^{I}$ Eng. Agr., Instituto Federal do Sudeste de Minas Gerais - Campus Barbacena, Barbacena - MG, Barbacena-MG, Brasil. \\ ${ }^{2}$ Professor do Instituto Federal do Sudeste de Minas Gerais, Núcleo de Zootecnia. Barbacena-MG Brasil. \\ ${ }^{3}$ Mestranda em zootecnia, Universidade Federal do Paraná, Departamento de zootecnia. Curitiba - PR, Brasil, \\ ${ }^{4}$ Eng. Agr., Msc., Universidade Federal de São João Del Rei, São João Del Rei-MG, Brasil, \\ ${ }^{5}$ Med. Veterinária, UNIPAC, Conselheiro Lafaiete - MG, Brasil, \\ *Autor para correspondência, E-mail:wellyngton.vilela@ifsudestemg.edu.br
}

\begin{abstract}
Resumo. O milho possui grande importância econômica, sendo o cereal mais produzido no mundo, e grande parte dessa produção é destinada para alimentação animal. Com o intuito de reduzir custos e riscos de produção, e aumentar a eficiência alimentar de ruminantes a silagem de milho reidratado se faz boa alternativa. O presente trabalho objetivou avaliar a qualidade da silagem de grão de milho reidratado sob quatro diferentes níveis de umidade. O experimento foi conduzido no Núcleo de Agricultura do Instituto Federal do Sudeste de Minas Gerais - Campus Barbacena. Foi utilizado delineamento inteiramente casualizado. Os tratamentos utilizados foram milho sem reidratação, milho reidratado à $30 \%$ de umidade, milho reidratado à $35 \%$ de umidade, milho reidratado à $40 \%$ de umidade e milho reidratado à $45 \%$ de umidade, com cinco repetições por tratamento, totalizando 25 silos experimentais. Após 56 dias de ensilagem foram feitas análises de matéria seca (MS), proteína bruta (PB), Matéria Mineral (MM) e pH. Os resultados demonstram que a qualidade da silagem foi influenciada em sua MS e $\mathrm{pH}$ pelos tratamentos com inclusão de água, atingindo valores de 70,74\% de MS e 5,01 de pH no tratamento com $45 \%$ de umidade. Não foi observado influência nos valores de PB e MM. Conclui-se que a inclusão de água influenciou a qualidade da silagem de milho grão reidratado.
\end{abstract}

Palavras chave: ensilagem, ruminantes, umidade

\section{Chemical evaluation of rehydrated corn silage at different water addition levels}

Abstract. Corn has great economic importance, being the most produced cereal in the world, and most of this production is destinated for animal feed. In order to reduce production costs and risks, and increase the feed efficiency of ruminants, rehydrated corn silage is a good alternative. The objective of this study was to evaluate the nutritional quality of rehydrated corn grain silage with four different levels of humidity. The experiment was conducted at the Agricultural Center in Federal Institute of Southeastern Minas - Campus Barbacena. The experimental design utilized was completely randomized. The treatments consisted of corn grain without reydratation (control), corn grain rehydrated with $30 \%$ moisture, corn grain rehydrated with $35 \%$ moisture, corn grain rehydrated at $40 \%$ moisture and corn grain rehydrated with $45 \%$ moisture, totaling 25 experimental silos. After 56 days the silos were opened and the levels of dry matter, crude protein, mineral mixture and $\mathrm{pH}$ were evaluated. The results showed that the quality of the silage was influenced in its DM and $\mathrm{pH}$ by the treatments with inclusion of water, reaching values of 
$70,74 \%$ of $\mathrm{MS}$ and 5,01 of $\mathrm{pH}$ in treatment with $45 \%$ of moisture. No influence was observed in $\mathrm{PB}$ and $\mathrm{MM}$ values. It was concluded tha the silage of rehydrated corn grain was influenced by the inclusion of water.

Keywords: ensilage, ruminants, moisture

\section{Evaluación química del ensilaje de maíz rehidratado a diferentes niveles de adición de agua}

Resumen. El maíz tiene una gran importancia económica, ya que es el cereal más
producido en el mundo, y gran parte de esta producción está destinada a la alimentación
animal. Para reducir los costos y riesgos de producción, y aumentar la eficiencia alimenticia
de los rumiantes, el ensilaje de maíz rehidratado es una buena alternativa. El presente
trabajo tuvo como objetivo evaluar la calidad del ensilaje de grano de maíz rehidratado
bajo cuatro niveles diferentes de humedad. El experimento se realizó en el Centro de
Agricultura del Instituto Federal del Sureste de Minas Gerais - Campus Barbacena. Se
utilizó un diseño completamente al azar. Los tratamientos utilizados fueron maíz sin
rehidratación, maíz rehidratado al $30 \%$ de humedad, maíz rehidratado al 35\% de humedad,
maíz rehidratado al $40 \%$ de humedad y maíz rehidratado al $45 \%$ de humedad, con cinco
repeticiones por tratamiento, totalizando 25 silos experimentales. Después de 56 días de
ensilaje, se analizaron materia seca (MS), proteína cruda (PC), materia mineral (MM) y
pH. Los resultados muestran que la calidad del ensilaje fue influenciada en su MS y pH por
los tratamientos con inclusión de agua, alcanzando valores de $70.74 \%$ MS y 5.01 pH en el
tratamiento con $45 \%$ de humedad. No se observó influencia en los valores de CP y MM.
Se concluyó que la inclusión de agua influyó en la calidad del ensilaje de maíz rehidratado.

Palabras clave: ensilaje, rumiantes, humedad

\section{Introdução}

O milho (Zea mays L.) é, possivelmente, o cereal com maior importância no cenário mundial, sendo o grão mais produzido no mundo, com cerca de 1,078 bilhão de toneladas na safra 2017/2018 (USDA, 2019). O Brasil é o terceiro maior produtor de milho. A maior parte dessa produção é destinada para a nutrição animal, que apresentou um aumento na demanda de $13,25 \%$ na safra 2018/2019, em relação à safra 2014/2015 (CONAB, 2018).

Por constituir grande parte das dietas de ruminantes, o milho influencia diretamente no preço e na viabilidade da atividade pecuária. Com o aumento nos preços dos fertilizantes devido à valorização do dólar frente ao real (CNA, 2018), o cenário apresenta dificuldades para pequenos, médios e grandes produtores. Assim, visando aumento da rentabilidade e viabilidade da produção, se faz necessário lançar mão de tecnologias que auxiliem na nutrição, com redução de custos e garantia de um padrão de qualidade ideal.

O processo de ensilagem do grão de milho reidratado se faz alternativa vantajosa nesse caso. Esse método de conservação consiste em adicionar água ao grão até que o mesmo atinja umidade ideal, para então ser ensilado. A utilização de milho úmido ensilado foi introduzida no Brasil em 1981, incialmente na produção de suínos e posteriormente em bovinos de corte e leite (Jobim et al., 2010). A técnica de reidratação e ensilagem do milho reduz o custo de transporte e armazenamento de grãos, o risco de ensilagem de grãos úmidos de milho devido à possibilidade de adquirir o milho de terceiros e ensilar na própria fazenda, e apresenta melhoras no aspecto nutritivo (Bitencourt, 2012).

O presente trabalho teve como objetivo avaliar a qualidade da silagem de grão de milho reidratado exposto a quatro diferentes níveis de inclusão de água.

\section{Material e métodos}

O experimento foi conduzido no município de Barbacena - MG (Latitude: $21^{\circ} 13^{\prime} 33^{\prime \prime} \mathrm{S}$, Longitude: $43^{\circ} 46^{\prime} 25^{\prime \prime} \mathrm{W}$ e altitude: 1164 metros), localizado na região da Serra da Mantiqueira, mesorregião do 
Campo das Vertentes, no Núcleo de Agricultura do Instituto Federal de Educação, Ciência de Tecnologia do Sudeste de Minas Gerais - Campus Barbacena (Silva, 2009).

O milho utilizado foi fornecido pelo Núcleo de Zootecnia do Instituto Federal, onde o mesmo é utilizado na nutrição na bovinocultura de leite. $\mathrm{O}$ material foi exposto à reidratação durante 24 horas, utilizando quatro níveis diferentes de adição de água, sendo eles: $30 \%, 35 \%, 40 \%$ e $45 \%$ de umidade em relação à matéria natural, além da silagem controle sem a adição de água, totalizando cinco tratamentos. Após esse processo, o milho grão foi ensilado em silos experimentais de PVC com dimensões de $300 \mathrm{~mm}$ de comprimento e $100 \mathrm{~mm}$ de diâmetro com capacidade de aproximadamente $2,3 \mathrm{~kg}$. Os silos possuem válvulas que permitem a saída dos gases da fermentação; porém, não permitem a entrada de ar no ambiente. Foram utilizados cinco silos laboratoriais por tratamento, com ou sem reidratação totalizando 25 silos. Os silos foram acondicionados no Laboratório Zootécnico do Núcleo de Zootecnia, em local sombreado e com temperatura ambiente.

A amostragem foi realizada 56 dias após a ensilagem, sendo os primeiros $5 \mathrm{~cm}$ das porções superior e inferior descartadas. Para as análises de composição química foram coletadas em duplicata e em todas as repetições amostras de $300 \mathrm{~g}$ da porção total da silagem, que posteriormente foram armazenadas em sacos de papel. Para a determinação da Matéria Seca foram pesadas em balança de precisão $100 \mathrm{~g}$ de matéria fresca de cada amostra descontando o peso do recipiente, e depois a pesagem após a secagem em estufa de ventilação forçada a $60^{\circ} \mathrm{C}$ por $72 \mathrm{~h}$, também descontando o peso do recipiente de utilizado.

Em seguida as amostras foram moídas em moinho de facas tipo Willey com peneira de $1 \mathrm{~mm}$ para determinação da proteína bruta $(\mathrm{PB})$ e cinzas realizadas pelo método micro Kjedahl, conforme $\mathrm{AOAC}$ (2005). A análise de $\mathrm{pH}$ foi determinada seguindo a metodologia dePhillip \& Fellner (1992).As análises foram realizadas no Laboratório de Solos do IF Sudeste MG - Campus Barbacena. A comparação estatística foi realizada com os dados obtidos no estudo de produção, por meio de uma análise de variância, em que as médias foram comparadas e testadas pelo método de TUKEY, ao nível de 5\% de probabilidade, através do programa SISVAR ${ }^{\circledR} 5.6$ (Ferreira, 2011).

\section{Resultados e Discussão}

Os teores de MS (Tabela 1) foram influenciados pelos tratamentos, observando-se uma redução de acordo com o aumento da inclusão de água, obtendo valores variando de 92,3\% para a silagem testemunha a 70,7\% para o tratamento com 45\% de inclusão de água. Mombach (2014) ao avaliarem MS em silagem de milho moído reidratado chegaram ao resultado de 54,28\% para tratamento com $40 \%$ de umidade ensilado por 42 dias, observando uma redução dos valores de MS de acordo com o aumento da inclusão de água. Menores valores de MS estão relacionados com o aumento de umidade nos tratamentos com mais inclusão de água. A redução dos valores de MS com o aumento na inclusão de água também foi observada neste experimento.Silva et al. (2016) avaliando estabilidade de silagens de grão úmido de milho e milho reidratado, atingiram valor de MS de 65,5\% em avaliação de milho reidratado a 35,0\% de umidade. De acordo com Faustino et al. (2018) caso a incorporação de água no milho não se dê por uma mistura vigorosa, a hidratação do grão não será perfeita, podendo resultar em perda do ensilado por crescimento de fungos. Os valores de MS encontrados no presente trabalho foram maiores que os encontrados por Mombach et al. (2019) e Silva et al. (2016), isso pode estar associado ao tratamento físico de moagem dos grãos utilizado pelos autores.Jobim et al. (2010) ao avaliarem a utilização de silagem de grão úmido de milho na alimentação de ruminantes, apontam que teores de umidade acima de $35 \%$ no momento da ensilagem de grão úmido de milho favorecem perdas de MS, podendo alterar os teores de nitrogênio e carboidratos solúveis. Fatores que podem ter influenciado os tratamentos com 35\%, 40\% e 45\% de inclusão de água.

Para valores de PB (Tabela 1), não houve diferença entre os resultados $(\mathrm{P}>0,05)$, sendo os teores médios variando entre $9,5 \%$ e $9,78 \%$. Wardynski et al. (1993) obtiveram resultados próximos, ao avaliarem silagem de grãos úmidos de milho com 76,8\% de MS, atingindo o valor de $9,0 \%$ de PB. Os valores obtidos no presente trabalho foram superiores ao valor de 8,7\% obtido por Morais et al. (2012) que associaram a variação dos teores de PB encontrados entre experimentos aos diferentes cultivares de milho utilizados.Mombach et al. (2019) obtiveram resultados diferentes do presente experimento, atingindo valores de $10,7 \%$ para tratamento sem inclusão de água e 9,4\% para tratamento com $40 \%$ de 
inclusão de água, associando a redução dos teores de PB à degradação dos compostos proteicos pela atividade dos microrganismos.

Velho et al.(2007) observaram que para animais em mantença, a silagem fornecida como único alimento deve apresentar valores de PB acima de 7\%, valor mínimo aceito como limitante do crescimento microbiano para manter a fermentação ruminal. Todos os valores de PB encontrados no experimento foram superiores a $7 \%$.

Tabela 1. Dados referentes aos teores médios de matéria seca (MS), proteína bruta (PB), matéria mineral (MM) e pH da silagem de grão de milho reidratado em quatro níveis diferentes de adição de água.

\begin{tabular}{lcccc}
\hline Tratamentos & MS & PB & MM & $\mathrm{pH}$ \\
\hline 1 & $92,348 \mathrm{a} 3$ & $9,558 \mathrm{a} 1$ & $1,684 \mathrm{a} 1$ & $5,300 \mathrm{a} 1 \mathrm{a} 2$ \\
2 & $74,418 \mathrm{a} 2$ & $9,776 \mathrm{a} 1$ & $1,566 \mathrm{a} 1$ & $5,468 \mathrm{a} 2$ \\
3 & $71,952 \mathrm{a} 1$ & $9,646 \mathrm{a} 1$ & $1,602 \mathrm{a} 1$ & $5,242 \mathrm{a} 1 \mathrm{a} 2$ \\
4 & $72,122 \mathrm{a} 1 \mathrm{a} 2$ & $9,516 \mathrm{a} 1$ & $1,578 \mathrm{a} 1$ & $5,368 \mathrm{a} 2$ \\
5 & $70,740 \mathrm{a} 1$ & $9,646 \mathrm{a} 1$ & $1,590 \mathrm{a} 1$ & $5,010 \mathrm{a} 1$ \\
\hline
\end{tabular}

*Médias seguidas por números distintos diferem entre si pelo teste de Tukey a 5\% de significância $(\mathrm{P}<0,05)$.

Os valores de $\mathrm{MM}$ não foram influenciados $(\mathrm{P}>0,05)$ pelos tratamentos, com resultados variando de 1,684 a 1,566. Resultados obtidos foram próximos ao observados por Mombach (2014) e Passini et al. (2002) que obtiveram valores de $1,47 \%$ e $1,66 \%$ respectivamente. Penteado et al. (2007) avaliando a inoculação de Lactobacillus plantarum em silagem de capim-Mombaça não observaram influência dos tratamentos sobre os teores de cinzas, assim como no presente experimento, obtendo valores de $11 \%, 10,8 \%, 10,7 \%$ e $10,9 \%$ para tratamentos com concentrações de inoculante de 0 , 104,105 e 106 respectivamente. Os autores apontam que a matéria mineral é pouco afetada pela fermentação no interior do silo.

Os valores de $\mathrm{pH}$ (Tabela 1) foram influenciados pelos tratamentos ocorrendo uma redução dos mesmos, com valores variando de 5,3 para a silagem controle a 5,01 para o tratamento com $45 \%$ de inclusão de água. Pinto (2009) ao avaliar qualidade da silagem de grão úmido de diferentes espécies chegou ao valor de $\mathrm{pH}$ de 4,0 para grão úmido de milho, indicando uma ocorrência de fermentação normal, valor inferior ao menor valor encontrado neste trabalho. Lopes et al. (2005) encontraram valor de $\mathrm{pH}$ de 4,29 para silagem de milho moído reidratado a $33 \%$ de umidade, inferindo que os valores de $\mathrm{pH}$ para silagem de milho reidratado são um pouco maiores do os valores encontrados em silagem e grão úmido (4-4,5). Valores esses, inferiores aos valores de $\mathrm{pH}$ encontrados no presente trabalho.

Segundo Neumann et al. (2007) a retirada do ar no silo, para consequente estabelecimento da condição de anaerobiose, acontece pela compactação, que é influenciada pelo teor de MS e pelo tamanho de partícula do material ensilado. Silagens com teor de MS maior que 60\%, como é o caso dos tratamentos deste experimento, normalmente não permitem uma compactação adequada. $\mathrm{O}$ valor de $\mathrm{pH}$ adequado depende principalmente do teor MS do material ensilado.

Jobim et al.(2007) apontam que atualmente o valor de $\mathrm{pH}$ de silagem deve ser usado com critério para análise da qualidade de fermentação, já que silagens com baixo teor de umidade possuem valores de $\mathrm{pH}$ elevados, maiores que 4,2, números que anteriormente eram utilizados para classificar uma silagem como de baixa qualidade. De acordo com Muck (2010) a partir do momento em que se estabelece condição de anaerobiose na silagem as bactérias ácido-láticas crescem rapidamente se tornando os microrganismos dominantes, produzindo ácidos orgânicos por meio da fermentação de açúcares, levando ao declínio dos valores de $\mathrm{pH}$.

Neumann et al. (2007) propõem uma classificação da qualidade do processo fermentativo de silagens em relação ao valor de $\mathrm{pH}$ associado ao conteúdo de MS, onde silagens com teores de MS acima de $40 \%$ possuem maior pontuação em relação à qualidade de fermentação com valores de $\mathrm{pH}$ variando de 4,6 a 4,8. Valores de $\mathrm{pH}$ de 4,8 a 5,2 possuem pontuação média, faixa em que é encontrado o pH de 5,01 obtido no tratamento com $45 \%$ de inclusão de água do presente trabalho. 


\section{Referências bibliográficas}

AOAC. (2005). - Association Official Analytical Chemist. In A. O. A. Chemist (Ed.), Official Methods of Analysis (Official M). AOAC.

Bitencourt, L. L. (2012). Substituição de milho moido por milho reidratado e ensilado ou melaço de soja em vacas leiteiras. UFLA.

CNA, Confederação de Agricultura e Pecuária do Brasil.; CEPEA, Centro de Estudos Avançados em Economia Aplicada. Encarecimento de insumos e queda dos preços dos produtos agropecuários pressionam o PIB do agronegócio em agosto de 2018. CEPEA; CNA, 2018.

CONAB, Companhia Nacional de Abastecimento. Análise Mensal. Maio/2018.

EMPRESA BRASILERA DE PESQUISA AGROPECUÁRIA - EMBRAPA. Avaliação da aptidão agrícola das terras da Zona das Vertentes - MG. Boletim de Pesquisa e Desenvolvimento 91, dezembro, 2006a, 58p.

Faustino, T. F., Dias, N. C., Leite, R. F., Silva, F. F. G., Florentino, L. A., \& Rezende, A. V. (2018). Utilização da silagem de grão de sorgo reidratado na alimentação animal. Nucleus Animalium, 10(2), 47-60. DOI: https://doi.org/10.3738/21751463.2892

Ferreira, D. F. (2011). SISVAR: A Computer Statistical Analysis System. Ciência e Agrotecnologia, 35(6), 1039-1042. DOI: https://doi.org/10.1590/s1413-70542011000600001

Jobim, C. C., Branco, A. F., Gai, V. F., Calixto Junior, M. C., \& Santos, G. T. (2010). Quality of high moisture corn grain silage with addition of raw soybean grains and parameters of partial and total digestibility in cattle. Qualidade Da Silagem de Grãos de Milho Com Adição de Soja Crua e Parâmetros de Digestibilidade Parcial e Total Em Bovinos, 62(1), 107-115. DOI: https://doi.org/10.1590/s0102-09352010000100015

Jobim, C. C., Nussio, L. G., Reis, R. A., \& Schmidt, P. (2007). Avanços metodológicos na avaliação da qualidade da forragem conservada. Revista Brasileira de Zootecnia, 36(Especial), 101-119. DOI: https://doi.org/10.1590/s1516-35982007001000013

Lopes, A. B. R. C., Biaggionni, M. A. M., Berto, D. A., Sartori, J. R., \& Boff, C. E. (2005). Método de reconstituição da umidade grãos de milho e a composição química da massa ensilada. Bioscience Journal, 21(1), 95-101.

Mombach, M A, Pereira, D. H., Pina, D. S., Bolson, D. C., \& Pedreira, B. C. (2019). Silage of rehydrated corn grain. Arquivo Brasileiro de Medicina Veterinária e Zootecnia, 71(3), 959-966. DOI: https://doi.org/10.1590/1678-4162-9676

Mombach, Mircéia Angele. (2014). Silagem de grão de milho triturado e reidratado contendo glicerina bruta e inoculante microbiano. Instituto de Ciências Agrarias e Ambientais.

Morais, M. da G., Ítavo, C. C. B. F., Ítavo, L. C. V., Bungenstab, D. J., Ribeiro, C. B., Oliveira, L. B., \& Silva, J. A. (2012). Inoculação de silagens de grãos úmidos de milho, em diferentes processamentos. Revista Brasileira de Saúde e Produção Animal, 13(4), 969-981. DOI: https://doi.org/10.1590/s1519-99402012000400002

Muck, R. E. (2010). Silage microbiology and its control through additives. Revista Brasileira de Zootecnia, 39(Supl), 183-191. DOI: https://doi.org/10.1590/s1516-35982010001300021

Neumann, M., Mühlbach, P. R. F., Nörnberg, J. L., Ost, P. R., Restle, J., Sandini, I. E., \& Romano, M. A. (2007). Características da fermentação da silagem obtida em diferentes tipos de silos sob efeito do tamanho de partícula e da altura de colheita das plantas de milho. Ciência Rural, 37(3), 847-854. DOI: https://doi.org/10.1590/s0103-84782007000300038

Passini, R., Silveira, A. C., Titto, E. A. L., Rodrigues, P. H. M., Beni Arrigoni, M., Costa, C., \& Chardulo, L. A. L. (2002). Silagem de grãos úmidos de milho e de sorgo e níveis protéicos sobre desempenho e características da carcaça de novilhos superprecoces. Acta Scientiarum. Animal Sciences, 24, 1133-1140. DOI: https://doi.org/10.4025/actascianimsci.v24i0.2600

Penteado, D. C. S., Santos, E. M., Carvalho, G. G. P., Oliveira, J. S., Zanine, A. M., Pereira, O. G. E., \& Ferreira, C. L. L. F. (2007). Inoculação com Lactobacillus plantarum da microbiota em silagem de capim-mombaça. Archivos de Zootecnia, 56(214), 191-202. 
Phillip, L. E., \& Fellner, V. (1992). Effects of bacterial inoculation of high-moisture ear corn on its aerobic stability, digestion, and utilization for growth by beef steers. Journal of Animal Science, 70(10), 3178-3187. DOI: https://doi.org/10.2527/1992.70103178x

Pinto, R. S. (2009). Qualidade da silagem de grãos úmidos de diferentes espécies. Universidade Federal de Goiás.

Silva, C. M., Amaral, P. N. C. do, Baggio, R. A., Tubin, J. S. B., Conte, R. A., Pivo, J. C. D., Krahl, G., Zampar, A., \& Paiano, D. (2016). Estabilidade de silagens de grãos úmidos de milho e milho reidratado. Revista Brasileira de Saúde e Produção Animal, 17(3), 341-343. DOI: https://doi.org/10.1590/s1519-99402016000300001

Silva, F. C. (2009). Manual de análises químicas de solos, plantas e fertilizantes. In EMBRAPA (Vol. 1). Embrapa Informação Tecnológica.

USDA, U. S. D. O. A. Grain: World Markets and Trade. Disponível em: <https://apps.fas.usda.gov/psdonline/circulars/grain.pdf>. Acesso em: 09 set. 2019.

Velho, J. P., Mühlbach, P. R. F., Nörnberg, J. L., Velho, I. M. P. H., Genro, T. C. M., \& Kessler, J. D. (2007). Composição bromatológica de silagens de milho produzidas com diferentes densidades de compactação. Revista Brasileira de Zootecnia, 36(5), 1532-1538. DOI: https://doi.org/10.1590/s1516-35982007000700011

Wardynski, F. A., Rust, S. R., \& Yokoyama, M. T. (1993). Effect of microbial inoculation of highmoisture corn on fermentation characteristics, aerobic stability, and cattle performance. Journal of Animal Science, 71(8), 2246-2252. DOI: https://doi.org/10.2527/1993.7182246x

Recebido: 27 de abril, 2020.

Aprovado: 12 de junho, 2020.

Disponível online: 31 julho, 2020.

Licenciamento: Este artigo é publicado na modalidade Acesso Aberto sob a licença Creative Commons Atribuição 4.0 (CC-BY 4.0), a qual permite uso irrestrito, distribuição, reprodução em qualquer meio, desde que o autor e a fonte sejam devidamente creditados. 